\title{
ORIGINAL RESEARCH \\ Strategies for Discussing Firearms Storage Safety in Primary Care: Veteran Perspectives
}

\author{
Steven K. Dobscha, MD ${ }^{1,2}$ (D), Khaya D. Clark, $P h D^{7}$, Summer Newell, $P h D, M P H^{7}$, \\ Emily A. Kenyon, $B A^{7}$, Elizabeth Karras, $P h D^{3}$, Joseph A. Simonetti, MD, $M P H^{4,5}$, and \\ Martha Gerrity, MD, MPH', \\ 'VA Center to Improve Veteran Involvement in Care (CIVIC), VA Portland Health Care System, Portland, OR, USA; ${ }^{2}$ Department of Psychiatry, \\ Oregon Health \& Science University, Portland, OR, USA; ${ }^{3}$ VA Center of Excellence for Suicide Prevention, Canandaigua, NY, USA; ${ }^{2}$ Rocky Mountain \\ Mental IIIness, Research, Education and Clinical Center (MIRECC) for Suicide Prevention, VHA, Aurora, CO, USA; ${ }^{5}$ Denver-Seattle Center of \\ Innovation for Veteran-Centered and Value-Driven Care, VHA, Aurora, CO, USA; ${ }^{\circ}$ Division of General Medicine, Oregon Health \& Science \\ University, Portland, OR, USA; ${ }^{7}$ Section of General Medicine, VA Portland Health Care System, Portland, OR, USA.
}

BACKGROUND: Two-thirds of veteran suicides are attributable to firearm injury. Although half of veterans who die by suicide are seen in primary care settings in the month prior to death, little is known about how to promote firearm safety within primary care.

OBJECTIVE: Describe veterans' perspectives on discussing firearms storage safety (FSS) during primary care visits, and identify key strategies for primary care teams to use in discussing FSS with veterans at elevated risk for suicide.

DESIGN: Qualitative analysis of transcripts and notes from four veteran focus groups and from individual semi-structured interviews with six veterans.

PARTICIPANTS: Altogether, 68 veterans participated. Three of the groups were associated with one Veterans Health Administration facility. Groups were diverse in age, service era, and gender.

APPROACH: The goals of the focus groups and interviews were to assess acceptance of FSS discussions during primary care visits, identify facilitators and barriers to conducting FSS discussions, and identify strategies for primary care teams to use to effectively conduct FSS discussions. Transcripts and meeting notes were analyzed using a grounded theory approach.

KEY RESULTS: There was general acceptance of having FSS discussions in primary care. Yet, most veterans did not support direct questioning about firearm ownership, which may trigger fears of having firearms taken away or limit access to firearms. Participants recommended primary care teams provide rationale for FSS discussions and be prepared to provide information on legal consequences of disclosing firearm ownership. Strategies suggested for primary care staff also included using a personalized, caring, and conversational approach rather than highly scripted or checklist approach, engaging veterans

Prior Presentations Society of General Internal Medicine Annual National Meeting in 2019: Clark KD, Gerrity M, Kenyon EA, Karras E, Simonetti JA, Dobscha SK. Means safety discussions for suicide prevention in primary care: Veteran and Veterans Health Administration (VHA) primary care team perspectives.

Received June 19, 2020

Accepted December 8, 2020

Published online January 26, 2021 in a non-judgmental manner, and conveying respect for veterans' knowledge of firearms.

CONCLUSIONS: Discussing FSS with veterans in primary care settings is a promising upstream approach that can complement other suicide prevention efforts, but must be conducted in a veteran-centric manner.

KEY WORDS: firearms safety; suicide; primary care.

J Gen Intern Med 36(6):1492-502

DOI: $10.1007 / \mathrm{s} 11606-020-06412-\mathrm{x}$

(C) This is a U.S. government work and not under copyright protection in the U.S.; foreign copyright protection may apply 2020

\section{INTRODUCTION}

Recent data show that veterans are 1.5 times more likely to die by suicide compared to non-veterans, ${ }^{1}$ and that the suicide rate among veterans is increasing more rapidly than among nonveterans. Many veterans have risk factors for suicide including older age, male gender, biopsychosocial stressors, and multiple medical and psychiatric co-morbidities. ${ }^{2}$ The Veterans Health Administration (VHA) is investing in efforts to move suicide prevention efforts "upstream," that is, to populations not necessarily known to be at high risk. These strategies include increases in mental health staffing, adoption of universal screening, greater outreach to the community, and training all VHA staff to recognize and respond to potential suicide risk.

Veterans are significantly more likely to use firearms as a means of suicide than the general population, ${ }^{3}$ and reducing access to lethal means is one of the few empirically supported approaches for lowering suicide rates. ${ }^{4,5}$ Safe firearms storage practices have been associated with reduced risk of death by suicide. ${ }^{6-8}$ Educating veterans about lethal means safety, and, in particular, firearms safety, has become an important component of upstream suicide prevention work. In this manuscript, we refer to firearms storage safety (FSS) discussions, which involves (1) advising veterans to keep firearms both locked and unloaded when not in use; and (2) strategizing about additional 
ways to reduce access to firearms in situations when there is greater risk for suicide, such as before or during a crisis.

Primary care is an especially important setting in which to identify and engage veterans at risk for suicide. Half of individuals, including veterans, who die by suicide are seen in primary care settings in the month prior to death. ${ }^{9}{ }^{10}$ Many veterans are reluctant to engage in specialty mental health services, ${ }^{11}$ and frequently receive all of their mental health treatment in primary care. ${ }^{12}$ Over the past decade, many healthcare systems, including VHA, have implemented standardized approaches to screening for mental health conditions, including suicidal ideation. While this screening effort is identifying patients with unmet mental health needs, it also provides a new opportunity to introduce FSS discussions into primary care. Positive mental health screens (e.g., depression, post-traumatic stress disorder [PTSD]) are designed to prompt further clinical assessment and patient-clinician discussions about mental health concerns. In this context, incorporating discussion of FSS may allow for intervention before a patient develops a crisis.

Research suggests that firearms discussions in non-mental health settings take place infrequently. ${ }^{13-15}$ Several reasons may explain this. Primary care clinicians are often uncomfortable discussing firearms with patients due to perceived barriers, such as little knowledge or personal experience with firearms, or concerns about negative impacts to the therapeutic alliance. ${ }^{16} \mathrm{Com}$ peting demands during brief appointments also likely limit the ability and willingness of primary care clinicians to discuss firearms, at least using more traditional lethal means safety counseling models. ${ }^{17,}{ }^{18}$ While some research has focused on veterans' attitudes and perceptions toward firearms discussions, ${ }^{19-21}$ we have identified no prior literature describing veterans' perspectives on participating in FSS discussions during primary care visits. The objectives of this study were to describe veterans' perspectives on participating in FSS discussions during VHA primary care visits and to identify key strategies for primary care teams to use in discussing FSS with veterans at elevated risk for suicide.

\section{METHODS}

\section{Setting and Sample}

The analysis and findings reported here are derived from the first phase of a larger project which sought to develop a training program on FSS for VHA primary care teams. This first phase, which was focused on developing content for the training, was designated as quality improvement activity by VA Portland Health Care System (VAPORHCS), a large, urban medical center in the Pacific Northwest. Three local veteran organizations were identified via word-of-mouth, and organization leadership was approached to set up focus group meetings. All members of these organizations were invited to the respective group meetings; thus, a convenience sample of veterans who were members of these organizations participated in focus groups.

Table 1 describes the purposes of each of the veteran groups and the number of participants in each. The veteran groups included (1) the Vancouver (Washington) Military Appreciation Committee, which promotes events in the community through a network of service agencies and programs; (2) the Veteran and Family Advisory Board, which is a group that engages in sharing information and knowledge among veterans' families to VAPORHCS and participates in the development of veteran and family satisfaction initiatives; and (3) the Veteran Engagement Group of the VHA Health Services Research and Development Center to Improve Veteran Involvement in Care (CIVIC) located at VAPORHCS.

Due to the nature of this quality improvement project, we did not collect individual-level data from focus group participants; most focus groups were held in the context of regular meetings of these organizations. However, in each of the groups, there was diversity in age, service era, and gender. Oregon is not very diverse in terms of race/ethnicity (e.g., $75 \%$ are White non-Hispanic ${ }^{22}$ ), and this was generally reflected in the groups. Due to firearms ownership being a sensitive issue, we intentionally did not ask individuals directly about firearms ownership. However, prior research indicates that approximately half of veterans own firearms, ${ }^{23}$ and we perceived during our meetings that the majority of participants either owned firearms, had positive attitudes toward firearms ownership, or indicated ownership by self-disclosure during the sessions. We also noted a general absence of comments indicating negative attitudes toward gun ownership.

In addition to the above three focus groups, a fourth group of veteran consultants, identified via communications with leaders of the above three groups, was created specifically to provide input into our project. This smaller group consisted of three post911 era firearm owners who had served in the Marines Corps, Air Force, and Army, respectively. Finally, six veterans completed individual, semi-structured interviews following the focus groups. Five of these individuals had participated in one of the focus groups, while the remaining individual was referred via word-of-mouth by a mental health clinician. Together, four men and two women from a variety of military branches participated in individual interviews: three who had served post-911, and two who had served in Vietnam. Altogether, 68 veterans participated in a focus group session and/or an individual interview.

\section{Data Collection}

We conducted hour-long, in-person focus groups in late 2018 and early 2019 with the four groups. Prior to the sessions, we developed a facilitation guide (Text Box 1) focused on (1) understanding attitudes toward firearms safety discussions; (2) understanding facilitators and barriers to firearms safety discussions in primary care; and (3) identifying knowledge and skills perceived to be important for conducting firearms safety discussions. Focus groups were moderated by the Project Lead, a psychiatrist (SKD), and the follow-up individual qualitative interviews were conducted in person by a sociologist (KDC). Each individual interview lasted approximately $60 \mathrm{~min}$. Three of the four focus groups and all of the interviews were audio recorded 


\section{Text Box. Firearms Storage Safety Project Interview Guides}

\section{Focus Group Session Guide}

- Introductory Comments

○ Thank you for allowing us to join you

- Introduction to Team

- We are hoping to record our conversation today so that we can completely and accurately capture your comments. When we transcribe the audiotapes, we will remove any identifying information so that your comments remain anonymous. Only our study team will have access to the transcripts. Are there any questions?

- Goals are to introduce you to the project and to obtain your input on the project

- Introduction to the Overall Project (development of training program)

○ Rationale

- Suicide prevention among veterans is a high priority

- Strong relationship between access to firearms and dying by suicide

- Veterans have high rates of gun ownership

- Firearms are the most common method of suicide among veterans

- Depression and PTSD increase risk for suicide

- Suicidal crises are often brief: Creating delays/barriers to accessing firearms during a time of crisis, even for a few minutes, can save lives

- Means Safety Counseling

- Clinician discusses firearms safety with patients

- Typically done in mental health settings and with individuals with known suicidal ideation

- Most patients who die by suicide don't receive specialty mental health care, but half of individuals who die by suicide see their primary care clinicians in the month prior to death

- Gather Input:

- How do people feel about the idea of primary care providers discussing means safety in primary care?

\section{Probes}

- How can primary care providers and their teams effectively deliver means safety messages to their patients?

○ What might be barriers or facilitators?

- How do people feel about the idea of our developing a training program for primary care teams on this topic?

\section{Probes}

- What are the most important messages for primary care providers to communicate to Veterans who screen positive for depression or PTSD? 
- What can we do to make sure these messages are delivered in a way that is acceptable and relevant to Veterans?

\section{Individual Interview Guide}

\section{Introduction}

Thank you for volunteering to participate in this interview. My name is X, and I am working with $\mathrm{X}$ on a means safety messaging project for primary care. Half of individuals, including Veterans, who die by suicide are seen in primary care in the month prior to death. Research suggests that safe firearm storage practices are associated with reduced risk of death by suicide: when lethal means are made less available to people who may attempt suicide impulsively.

In our study, we have developed some "talking points" that primary care staff can use to discuss firearms safety, particularly when patients screen positive for depression or posttraumatic stress disorder during a clinical visit. We hope that these means safety conversations will be brief (5-10 minutes). In this interview, I would like to get your feedback on: a) skills that staff should have to talk to patients about means safety in a way that is acceptable to patients, and b) the types of information that should be included in patient educational materials on weapons safety.

Before we begin, I would like to talk about the interview process. You can choose to skip any question if you feel uncomfortable. Also, our conversation will be recorded today so that I can completely and accurately capture your comments. When we transcribe the audiotapes, we will remove any identifying information (e.g. names, cities, etc.) so that your comments remain anonymous. Only our study team will have access to the actual transcripts. Do you have any questions before we begin?

So to get started with the interview, we need to obtain your verbal consent for the recording. Is it okay with you for us to record this interview?

\section{[IF YES, START RECORDER]}

I've started the recorder. Would you please state your name for the verbal consent process? Do you consent to being recorded to participate in this study?

Great, thank you.

1. First, can you tell me a little about yourself? Probes:

- How long have you been receiving care at the VA?

- In which branch of the military did you serve?

- What did you do during your military service (e.g., job)? 


\section{Educational Program for Providers/PACT members}

Now I would like to ask you several questions to get your thoughts on key elements of a training program for primary care providers and their staff.

2. Please describe key knowledge and skills that primary care providers and their staff should have to discuss firearms with Veterans.

Probes:

- What type of information should primary care providers and their staff know about firearm safety?

- Please describe strategies that staff could use to help Veterans feel comfortable with the conversation.

- Please describe any service era differences that might impact conversations about firearm safety in primary care.

3. Please share your thoughts on any educational materials that clinics could share with Veterans to make the topic of firearms safety a normal part of conversations that happen in primary care. What kinds of handouts could be helpful to reduce stigma related to mental health conditions?

Probes:

- Please describe the types of educational materials would be useful for Veterans.

- Please describe materials that would be useful for friends and family members of Veterans to heighten the awareness of how weapons and prescription safety practices are important for Veterans who are experiencing depression and PTSD.

4. If your doctor was concerned about your safety during a primary care visit, how would you like that conversation to go?

5. Has your provider ever wanted to discuss mental health and personal safety?

[If yes, probes]

- Did the conversation feel ok to have during a primary care visit?

- Has your provider explained the link between mental health and personal safety?

- Describe your level of satisfaction with the conversation (e.g., authentic).

- How satisfied were you with the provider's behavior during the conversation? 
Table 1 Veteran Group Description (Total Number of Participants from Groups $=68$ )

\begin{tabular}{|c|c|c|c|}
\hline Focus group & Location of organization/meeting & Participants & Description \\
\hline $\begin{array}{l}\text { Vancouver Community Military } \\
\text { Appreciation Committee (CMAC) }\end{array}$ & $\begin{array}{l}\text { CMAC Building (Community), } \\
\text { Vancouver, WA }\end{array}$ & 50 & $\begin{array}{l}\text { A } 501(\mathrm{c}) 3 \text { organization created to connect veteran } \\
\text { advocacy organizations in and around Southwest } \\
\text { Washington. CMAC's goal is to acknowledge and } \\
\text { appreciate every veteran's service to our country } \\
\text { by providing and promoting veteran events in the } \\
\text { community through a network of service agencies } \\
\text { and programs that have an interest in honoring and } \\
\text { supporting veterans and their families. }\end{array}$ \\
\hline $\begin{array}{l}\text { VA Portland Veteran and Family } \\
\text { Advisory Board (VFAB) }\end{array}$ & $\begin{array}{l}\text { VA Portland Executive Suite, } \\
\text { VA Portland Health Care System, } \\
\text { Portland, OR }\end{array}$ & 10 & $\begin{array}{l}\text { The Veteran and Family Advisory Board (VFAB) } \\
\text { promotes opportunities for cultural transformation } \\
\text { in both the practice and experience of health care } \\
\text { by coordinating and assisting with the voices of } \\
\text { veterans and their families throughout the VA } \\
\text { Portland Health Care System (VAPORHCS). The } \\
\text { goals of the VFAB are to improve the sharing of } \\
\text { information and knowledge among veterans, fam- } \\
\text { ilies, and the VAPORHCS; and enhance ongoing } \\
\text { collaboration and cooperation among clinicians, } \\
\text { veterans, and families for the benefit of veterans } \\
\text { receiving care. }\end{array}$ \\
\hline $\begin{array}{l}\text { Veteran Engagement Group-Center to } \\
\text { Improve Veteran Involvement in } \\
\text { Care (CIVIC) }\end{array}$ & $\begin{array}{l}\text { Research Service, VA Portland } \\
\text { Health Care system, Portland, OR }\end{array}$ & 5 & $\begin{array}{l}\text { The VEG is a platform for veterans to share their } \\
\text { perspectives with other veterans, researchers at the } \\
\text { Portland VA, and the larger veteran community. } \\
\text { By joining the CIVIC VEG, veterans help shape } \\
\text { the future of VA research and impact health care } \\
\text { for all veterans. }\end{array}$ \\
\hline $\begin{array}{l}\text { Current Project Veteran } \\
\text { consultant group }\end{array}$ & $\begin{array}{l}\text { Research Service, VA Portland } \\
\text { Health Care System, Portland, OR }\end{array}$ & 3 & $\begin{array}{l}\text { Three veterans were identified through existing } \\
\text { VA contacts to serve as consultants to the research } \\
\text { team and provide input on all phases of the } \\
\text { project. }\end{array}$ \\
\hline
\end{tabular}

and transcribed; detailed notes were taken for the remaining focus group due to unanticipated challenges of recording in a large room. All audio recordings were transcribed, de-identified, and validated for accuracy by an independent reviewer.

\section{Analysis}

We employed a grounded theory approach, using a two-phase analysis process informed by the work of Miller and Crabtree using open and axial coding procedures ${ }^{24-27}$ and principles of an immersion-crystallization process to guide the interpretive process. ${ }^{28}$ We followed the constant comparative method in which codes, participants, and categories are analyzed to identify consistencies and differences with a main aim toward conceptual refinement. ${ }^{24,26}$ Overall, this process involves a high degree of reflexivity in which the project team continually examines its assumptions, expectations, and how team identities influence the research process.

The lead qualitative analyst (KDC) reviewed all of the transcripts and notes and developed codes, which were organized using Atlas.ti (Version 7.0, Atlas.ti Scientific Software Development GmbH, Berlin, Germany). Pertinent sections of the texts were coded so that text could be clustered and further analyzed. The multidisciplinary team read and discussed the data as they were collected and coded; and the Project Lead (SKD), who has experience using qualitative methods, reviewed the coded transcripts and worked with the lead analyst to refine codes. In the second phase of the analysis, we examined patterns across the focus groups and interview data, collaboratively identifying key themes related to acceptance of FSS discussions during primary care appointments, facilitators and barriers to conducting FSS discussions, and skills or strategies for primary care teams to use to effectively conduct firearms safety discussions with veterans.

\section{RESULTS}

Several key themes arose from the analysis including that (1) most veterans generally agree that primary care is an acceptable setting for FSS discussions, but staff need to build rapport and trust by using a personal, caring, and non-judgmental approach; (2) veterans have special concerns about the legal consequences of disclosing firearm ownership; and (3) staff need to provide a rationale for FSS discussions. Across the focus groups and individual interviews, participants provided a number of suggestions that could facilitate effective discussions of FSS in primary care.

\section{Acceptance of Firearms Storage Safety Discussions in Primary Care}

Across the focus groups and individual interviews, veterans expressed general support for FSS discussions during primary care visits. However, many noted that the topic is sensitive, and had a number of recommendations for how FSS messages can be normalized and accepted by veterans. Several veterans noted that FSS discussions could be framed in the context of 
basic educational information, a health behavior framework, or from a military safety perspective:

"I think one other approach that might work is that you try to go from general to specific, you approach it from the standpoint of safety and security in the household. When I was asked 20 years ago it was along those lines: 'Do you have kids at home? Are you storing things safely?' so it's for the safety and security for all." (Group 2)

"...it might be effective if the message was delivered like in military training: health behavior and management, like taking medication and taking care of yourself and healthy relationship to firearms." (Group 4)

One veteran suggested tying FSS to the VHA Whole Health Initiative ${ }^{29}$ a holistic and patient-centered approach to health and well-being, stating,

"The VA is changing its mindset into a whole health approach, and this would be a nice tie into the whole health approach.” (Group 1)

\section{Building Rapport}

The desire to have FSS discussions personalized to the individual veteran was cited as an important strategy to engage veterans in firearms safety discussions, given the sensitive nature of the discussions. Veterans expressed negative attitudes toward formulaic screening processes and preferred more authentic connections with primary care staff. As one veteran explained:

"Yeah, I mean instilling them to be a little bit more sincere with the veterans they meet instead of just being like [In a disinterested tone] 'Hey you got a firearm at home? Okay, you know you should keep it locked up. Umm, next thing: you're a little overweight. Cool. You should probably go on a diet." (Group 1)

Another important aspect of engaging veterans in firearms safety discussions involves primary care staff conveying care for the health and well-being of veterans. As this veteran stated:

"Just explaining, 'This is why I'm asking you these questions. It's because I care, and I don't want to see you end up hurt.' You know, actually showing concern instead of just like 'Do you have_-' and reading off of a checklist." (Veteran 1)

Participants offered some key strategies for ways that primary care staff can build rapport and establish trust. One suggestion for establishing trust included making eye contact:
"Veterans are walking into VA saying "I don't trust you. It's going to take a lot of time before I trust you." You're not going to gain that trust if you're just looking at the screen and filling in the blanks. Take the time to look and get on that personal level. I'm not going to tell you if I don't trust you, and I can tell because you're not looking at me." (Group 3)

Veterans also told us that having a member of the team other than the provider talk with veterans about firearms safety would be a prudent approach mainly because veterans often know their nurses or medical assistants better than they know their providers. Provider turn-over was cited several times as a key reason that veterans might feel less comfortable discussing firearms safety with providers. As one respondent stated:

"If there's going to be staff here that that does that [discussion of firearms safety], they need to be the same person.... If I'm going to open up to somebody it's gonna be somebody I trust. Not just somebody that says 'Doctor'.' (Veteran 2)

\section{Non-judgmental Approach}

Veterans also shared their experiences of feeling judged by providers after disclosing firearm ownership and cautioned that primary care staff should try to refrain from making veterans feel shame about owning a firearm. As one veteran recalled,

"I've gotten it. 'Do you have a firearm?' I'm like, 'yeah.' And they're like 'Hmmm [imitates doctor looking down and writing something with a displeased expression]." (Group 1).

Another veteran cautioned that primary care staff should be aware of verbal and non-verbal expressions of judgment in interactions with veterans during firearms safety discussions,

"I remember just the general shock at providers when they're like 'Do you own firearms?' and I said, 'yeah.' And they go 'Oh my god,' and they start looking at me weird where they'd scoot over across the room, so their behaviors, their reactions are just something that need to be worked on." (Veteran 5)

\section{Legal Consequences of Disclosure}

Multiple veterans relayed concerns about the legal ramifications of disclosing firearms ownership, primarily of having their weapons confiscated or fear of having information included in their records, or being put on a list of firearm owners which could limit access to firearms in the future. Veterans from three of the four focus groups said that primary care staff should avoid asking veterans direct 
questions about firearm ownership because veterans would frequently not tell them the truth. For example, one veteran stated that he did not want his provider to know that he has firearms because,

"I don't trust the State in not confiscating my weapons." (Group 4)

And,

"Yeah, to piggyback on that, a lot of Vets are afraid to-like if the doc's like, 'Hey, do you have a gun at home?' They're going to be like 'Nope...Like I'm not going to tell you that..." (Group 1)

Another veteran said:

"You just exposed every veteran's fear in this, because they know that the doctor has a buzzer right there. He's already buzzed the security guys. That just to me screams just like "we're coming to get you." (Veteran 4)

Disclosure of ownership was of special concern to veterans with mental health conditions. As one veteran said,

"... if I ever did want to get a gun because of civil unrest, and I felt like I needed to protect myself, am I already on a 'can't get gun list' because I have PTSD?" (Group 3)

Another said in the same context:

“Then also until 2011 we weren't even allowed to have mental health issues, including PTSD, we had to hide it because we'd lose our security clearance. So, there's a lot of avoidance of talking about mental health issues that confound this." (Veteran 1)

To help address fears about disclosure, this veteran also suggested that primary care staff should have up-to-date knowledge on state and federal laws regarding firearm safety:

"I think it's important to know the Oregon state laws surrounding firearms safety and firearms. I know a lot of people don't know the laws surrounding that, and then they want to give advice like 'well, just give your firearm to a friend' or 'give it to a loved one,' but there needs to be more education surrounding what are the repercussions of doing that, and what are the laws about doing that." (Veteran 1)

\section{Providing a Rationale}

Finally, veterans told us that other veterans would be more accepting of FSS discussions in primary care if they more clearly understood the reasons for why discussions are happening. Participants gave input on different ways that providers can provide a context for these discussions. For example, one participant noted the following:

"I think that explaining why you're talking to the person about it is a good thing because if you don't explain why you're talking to somebody about something they're going to be like, 'Where is this coming from? Why are you—?' would be helpful.” (Group 1)

One strategy suggested to contextualize discussions would be for staff to frame the discussion around VA initiatives to promote mental health. As a respondent stated:

"Maybe just one more thing. Letting veterans in general know that the VA is improving their accessibility and variety of mental health care treatments, like CBT [cognitive behavioral therapy]. 'Oh hey, I noticed you're not sleeping a lot' and just making sure they're aware of what's available.'” (Group 3)

Finally, several veterans offered actual "scripts" that providers could use to directly engage veterans about firearms without asking about whether a veteran owns a firearm:

"Hey, I know you're a veteran and a lot of you guys own guns. I don't care if you do or don't. I would encourage you to add some barriers between you and your weapon, whether that be removing a firing pin, or handing your [gun lock] keys to a spouse. Don't do something you can't take back." (Group 3)

"Do you have a way to secure your firearm? Is it currently safe? If not, how can we help you secure that firearm and what would be the most useful tool to you?" (Veteran 5)

An additional suggestion was to refrain from making assumptions or claims about one's mental health and ability to handle a firearm. As one veteran noted,

"Just kind of not saying like 'not in the right state of mind' to be handling weapons...it's sort of off putting, almost like you are saying 'you're kind of crazy sometimes, and so maybe you should not have your firearms'." (Veteran 2)

\section{DISCUSSION}

Our findings indicate that, while many veterans are supportive of engaging in FSS discussions during primary care visits, the 
topic is considered sensitive, and there are important aspects that must be incorporated to make FSS discussions acceptable to, and effective for, veterans. These include providing a clear rationale for FSS discussions, the need to build rapport and trust through a personal, caring, and non-judgmental approach, and being aware of veterans' concerns about legal consequences of firearms disclosure. Specifically, veterans did not support direct queries about firearm ownership (e.g., "Do you own a firearm or weapon?"), which can trigger fears of having firearms taken away or being put on a registry that could limit access to firearms. Assumptions should also not be made about the ability of a veteran experiencing depression or PTSD to handle firearms.

Our main finding that veterans believe such discussions are acceptable under some circumstances is consistent with other works showing that veterans, ${ }^{16}$ other patient groups, ${ }^{20,30,31}$ and clinicians ${ }^{16,32}$ are willing to discuss FSS, especially when discussions are conducted in a culturally sensitive, nonjudgmental manner ${ }^{33-35}$ and patients are made aware of the discussion's direct relevance to the patient's safety and wellbeing. ${ }^{36}$ This includes veterans who receive VHA mental health care: in one survey of veterans receiving depression treatment within VHA, 93\% endorsed one or more health systems interventions aimed at reducing veterans' access to firearms during high-risk periods. ${ }^{37}$

However, there are several contextual factors that are important to keep in mind. Some prior research suggests that the perceived credibility of physicians as messengers regarding firearms safety may be limited. ${ }^{38-40}$ Other factors that likely impact patient perceptions of FSS discussions include patient trust in the provider, the manner in which messages are communicated, perceived relevance to care, and legal considerations (in particular, fears of restrictions of rights to firearms). ${ }^{21,34,35,41,42}$ Research has also shown that veterans may have unique attitudes relevant to firearms discussions, including frequently perceiving firearms as necessary for protection and as serving an important social function. ${ }^{16,21,23,43}$

Our findings have several implications for practice and development of training approaches for primary care teams. First, in some cases, it may not be most productive to directly ask about firearms ownership, especially if suicide risk is not considered high or if the staff member does not have a solid working relationship with the veteran. Given that nearly half of all veterans own firearms, ${ }^{23}$ one approach to FSS is to initiate FSS discussions in conjunction with mental health screening, "assuming" that the veteran may own a firearm and allowing him or her to actively engage in the conversation, even if it is to inform the clinician he/she does not own one. This approach may allow for more natural conversations (vs. scripted discussions) to occur, which may facilitate further disclosure of topics pertinent to FSS (e.g., personal significance of firearm ownership, training/experience, household storage practices). Second, framing communication with a veteran-centered rationale (e.g., concern for veteran household safety and well-being) and acknowledging legal implications may loosen constraints or reduce discomfort surrounding FSS and begin to normalize these types of conversations as part of routine care. Involving team members who have strong relationships with veterans may provide greater opportunity to provide or improve the outcome of FSS discussions. We note that many VHA primary care staff members are veterans ${ }^{44}$; increasing their involvement may be helpful in enhancing credibility of FSS messaging. Staff would also benefit from training or having supplemental information available on legal questions that may arise; we note that there is considerable state variation in firearms transfer laws ${ }^{45}$; guidance will need to take this into account. Finally, it is critical that staff be aware of any biases they may have about firearms - such biases can be inadvertently communicated and have the potential to limit productive discussion. While it is essential to acknowledge veteran perspectives on best practices in primary care, implementing some of these suggestions may pose challenges in the primary care context. Primary care providers are under a great deal of pressure ${ }^{46}$ to address multiple health and safety concerns in a short amount of time; additional requirements may add to this pressure.

\section{Limitations}

We enlisted several convenience samples to provide data for this project, and most veterans who participated lived in a large west coast urban area, which may not reflect perspectives of those in rural locations or in other parts of the country. We did not collect individual-level demographic information from the participants. Due to the small number of focus groups and lack of individual-level data, it was challenging to make comparisons between different demographic subpopulations. Follow-up exploration with a larger, more diverse sample would be helpful, including more veterans not utilizing VHA care. In addition, as this study relies solely on qualitative interviews, we are not able to draw definitive conclusions from the data; rather, findings should be used as a starting point for more deductive exploration. Future research should triangulate provider and patient perspectives of firearm-related conversations, and test different communication strategies for behavior change.

\section{CONCLUSION}

As an upstream approach to suicide prevention, primary care teams have the opportunity to encourage patients to take steps to improve household safety and reduce risk for suicide by putting distance between their firearms and themselves, particularly during times of emotional distress. Because the majority of veterans and other patients with common psychiatric disorders, such as PTSD and depression, do not receive treatment in specialty mental health settings, ${ }^{41}$ it is essential that primary care teams be prepared to discuss FSS with their atrisk patients. Furthermore, many veterans do not receive VHA care, and some may not routinely receive healthcare; as such, it 
is important to continue to develop multifaceted approaches to improving firearms safety that go beyond the VHA and healthcare settings. As our findings highlight, while firearms discussions can be a sensitive topic, veterans are open to these discussions if primary care teams approach the topic appropriately.

Corresponding Author: Steven K. Dobscha, MD; VA Center to Improve Veteran Involvement in Care (CIVIC), VA Portland Health Care System, Portland, OR, USA (e-mail: Steven.Dobscha@va.gov).

Funding This material is based upon work supported by the Department of Veterans Affairs, Veteran Health Administration, Office of Mental Health and Suicide Prevention and Health Services and Research and Development Center to Improve Veteran Involvement in Care (CIVIC) (CIN 13-404).

\section{Compliance with Ethical Standards:}

Conflict of Interest: The authors declare that they do not have a conflict of interest.

Disclaimer: The views expressed in this article are those of the authors and do not necessarily reflect the position or policy of the Department of Veterans Affairs or the United States Government.

\section{REFERENCES}

1. Office of Mental Health and Suicide Prevention. VA National Suicide Data Report 2005-2015. 2018.

2. Department of Veterans Affairs and Department of Defense. VA/DoD Clinical Practice Guideline for the Assessment and Management of Patients at Risk for Suicide. 2019.

3. Anestis MD, Bryan CJ. Means and capacity for suicidal behavior: a comparison of the ratio of suicide attempts and deaths by suicide in the US military and general population. J Affect Disord 2013;148(1):42-47.

4. Mann JJ, Apter A, Bertolote J, Beautrais A, Currier D, Haas A, et al. Suicide prevention strategies: a systematic review. JAMA 2005;294(16):2064-74.

5. Bagley SC, Munjas B, Shekelle P. A systematic review of suicide prevention programs for military or veterans. Suicide Life Threat Behav 2010;40(3):257-65.

6. Conwell Y, Duberstein PR, Connor K, Eberly S, Cox C, Caine ED Access to firearms and risk for suicide in middle-aged and older adults. Am J Geriatr Psychiatry 2002;10(4):407-416.

7. Shenassa ED, Rogers ML, Spalding KL, Roberts MB. Safer storage of firearms at home and risk of suicide: a study of protective factors in a nationally representative sample. $\mathrm{J}$ Epidemiol Community Health 2004;58(10):841-848.

8. Dempsey CL, Benedek DM, Zuromski KL, Riggs-Donovan C, Ng THH, Nock MK, et al. Association of firearm ownership, use, accessibility, and storage practices with suicide risk among US Army Soldiers. JAMA Netw Open 2019;2(6):e195383.

9. Denneson LM, Kovas AE, Britton PC, Kaplan MS, McFarland BH, Dobscha SK. Suicide risk documented during veterans' last veterans affairs health care contacts prior to suicide. Suicide Life Threat Behav 2016

10. Luoma JB, Martin CE, Pearson JL. Contact with mental health and primary care providers before suicide: a review of the evidence. Am J Psychiatry 2002;159(6):909-16.

11. Cheney AM, Koenig CJ, Miller CJ, Zamora K, Wright P, Stanley R, et al. Veteran-centered barriers to VA mental healthcare services use. BMC Health Serv Res 2018;18(1):591-018-3346-9.

12. Leung LB, Yoon J, Rubenstein LV, Post EP, Metzger ME, Wells KB, et al. Changing patterns of mental health care use: the role of integrated mental health services in veteran affairs primary care. J Am Board Fam Med 2018;31(1):38-48.

13. Dobscha SK, Denneson LM, Kovas AE, Corson K, Helmer DA, Bair MJ. Primary care clinician responses to positive suicidal ideation risk assessments in veterans of Iraq and Afghanistan. Gen Hosp Psychiatry 2014;36(3):310-317.

14. Naureckas C, Sacks CA, McGregor KA, Masiakos PT, Flaherty MR Screening for access to firearms by pediatric trainees in high-risk patients. Acad Pediatr 2019;19:659-664

15. Naganathan S, Mueller KL. Physician documentation of access to firearms in suicidal patients in the emergency department. West $\mathrm{J}$ Emerg Med 2019;20:818-821

16. Walters H, Kulkarni M, Forman J, Roeder $\mathbf{K}$, Travis J, Valenstein $\mathbf{M}$ Feasibility and acceptability of interventions to delay gun access in VA mental health settings. Gen Hosp Psychiatry 2012;34(6):692-698.

17. Suicide Prevention Resource Center. CALM: Counseling on Access to Lethal Means online course. Available at: http://www.sprc.org/resources-programs/calm-counseling-access-lethal-means. Accessed Sept 11, 2020

18. Means Matter, Harvard T.H. Chan School of Public Health. Lethal Means Counseling: Recommendations for Clinicians. Available at: https://www. hsph.harvard.edu/means-matter/recommendations/clinicians /. Accessed Sept 11, 2020.

19. Roszko PJ, Ameli J, Carter PM, Cunningham RM, Ranney ML. Clinician attitudes, screening practices, and interventions to reduce firearm-related injury. Epidemiol Rev 2016;38(1):87-110.

20. Betz ME, Flaten HK, Miller M. Older adult openness to physician questioning about firearms. J Am Geriatr Soc 2015;63(10):2214-2215.

21. Simonetti JA, Dorsey Holliman B, Holiday R, Brenner LA, Monteith LL. Firearm-related experiences and perceptions among United States male veterans: a qualitative interview study. PLoS One 2020;15(3):e0230135.

22. Deloitte, Datawheel. Data USA: Oregon. Available at: https://datausa.io/ profile/geo/oregon\#: :text=The\%205\%20largest\%20ethnic\%20groups ,and\%2094.4\%25\%20are\%20U.S.\%20citizens. Accessed 8/31, 2020.

23. Cleveland EC, Azrael D, Simonetti JA, Miller M. Firearm ownership among American veterans: findings from the 2015 National Firearm Survey. Inj Epidemiol 2017 4(1):33-017-0130-y.

24. Corbin J, Strauss A. Basics of Qualitative Research: Techniques and Procedures for Developing Grounded Theory. 4th Thousand Oaks: Sage publications; 2014.

25. Charmaz K. Constructing Grounded Theory: a Practical Guide Through Qualitative Analysis. London; Thousand Oaks: Sage; 2006.

26. Creswell JW, Poth CN. Qualitative Inquiry and Research Design: Choosing Among Five Approaches. Thousand Oaks: Sage publications; 2016

27. Miller WL, Crabtree BF. The dance of interpretation. In: Crabtree BF, Miller WL, editors. Doing Qualitative Research. 2nd Thousand Oaks: Sage Publications; 1999. p. 127-143.

28. Borkan J. Immersion/Crystallization. In: Crabtree BF, Miller WL, editors Doing Qualitative Research. 2nd Thousand Oaks: Sage Publications; 1999.

29. Office of Patient Centered Care and Cultural Transformation: Promoting Whole Health. 2015; Available at: http://www.va.gov/ PATIENTCENTEREDCARE/components-health-well-being.asp. Accessed 17 Dec 2020.

30. Betz ME, Azrael D, Barber C, Miller M. Public opinion regarding whether speaking with patients about firearms is appropriate: results of a national survey. Ann Intern Med 2016;165(8):543-550.

31. Boge LA, Dos Santos C, Burkholder JD, Koschel BR, Cubeddu LX, Farcy DA. Patients' perceptions of the role of physicians in questioning and education in firearms safety: post-FOPA repeal era. South Med J 2019;112:34-38.

32. Cassel CK, Nelson EA, Smith TW, Schwab CW, Barlow B, Gary NE. Internists' and surgeons' attitudes toward guns and firearm injury prevention. Ann Intern Med 1998; 128(3):224-230.

33. Marino E, Wolsko C, Keys S, Wilcox H. Addressing the cultura challenges of firearm restriction in suicide prevention: a test of public health messaging to protect those at risk. Arch Suicide Res 2017 27:1-11.

34. Stanley IH, Hom MA, Rogers ML, Anestis MD, Joiner TE. Discussing firearm ownership and access as part of suicide risk assessment and prevention: "means safety" versus "means restriction". Arch Suicide Res 2017;21(2):237-253.

35. Betz ME, Wintemute GJ. Physician counseling on firearm safety: a new kind of cultural competence. JAMA 2015;314(5):449-450.

36. Sege RD, Hatmaker-Flanigan E, De Vos E, Levin-Goodman R, Spivak H. Anticipatory guidance and violence prevention: results from family and pediatrician focus groups. Pediatrics 2006;117(2):455-463.

37. Valenstein M, Walters H, Pfeiffer PN, Ganoczy D, Miller M, Fiorillo M, et al. Acceptability of potential interventions to increase firearm safety 
among patients in VA mental health treatment. Gen Hosp Psychiatry 2018 55:77-83.

38. Crifasi CK, Doucette ML, McGinty EE, Webster DW, Barry CL. Storage practices of US gun owners in 2016. Am J Public Health 2018;108(4):532-537.

39. Knoepke CE, Allen A, Ranney ML, Wintemute GJ, Matlock DD, Betz ME. Loaded questions: internet commenters' opinions on physicianpatient firearm safety conversations. West J Emerg Med 2017; 18(5):903912.

40. Shaughnessy AF, Cincotta JA, Adelman A. Family practice patients' attitudes toward firearm safety as a preventive medicine issue: a HARNET Study. Harrisburg Area Research Network. J Am Board Fam Pract 1999; 12(5):354-359.

41. National Academies of Sciences, Engineering, and Medicine, Health and Medicine Division, Board on Health Care Services, Committee to Evaluate the Department of Veterans Affairs Mental Health Services. Evaluation of the Department of Veterans Affairs Mental Health Services. NAP 2018.
42. Wintemute GJ, Betz ME, Ranney ML. Yes, You can: physicians, patients, and firearms. Ann Intern Med 2016;165(3):205-213.

43. Simonetti JA, Azrael D, Rowhani-Rahbar A, Miller M. Firearm storage practices among American veterans. Am J Prev Med 2018;55(4):445-454.

44. Office of Public Affairs Media Relations. VA celebrates workforces, unions and veterans. Available at: https://www.va.gov/opa/pressrel/ pressrelease.cfm?id=1950. Accessed 6/17, 2020.

45. McCourt AD, Vernick JS, Betz ME, Brandspigel S, Runyan CW. Temporary transfer of firearms from the home to prevent suicide: legal obstacles and recommendations. JAMA Intern Med 2017;177(1):96-101.

46. Rost K, Nutting P, Smith J, Coyne JC, Cooper-Patrick L, Rubenstein L. The role of competing demands in the treatment provided primary care patients with major depression. Arch Fam Med 2000;9(2):150-4.

Publisher's Note: Springer Nature remains neutral with regard to jurisdictional claims in published maps and institutional affiliations. 